Article

\title{
Influence of Post-Weld Heat Treatments on Microstructure and Mechanical Properties of Laser Beam Welded 2060-T3/2099-T3A1-Li T-Joints
}

\author{
Yunlong Zhang ${ }^{1, *}$, Yanbin Chen ${ }^{1,2, *}$, Wang Tao ${ }^{1}$, Zhenglong Lei ${ }^{1} \mathbb{D}$, Zhaohui Yang ${ }^{2}$ \\ and Tiantian Nan ${ }^{3}$ \\ 1 State Key Laboratory of Advanced Welding and Joining, Harbin Institute of Technology, Harbin 15001, \\ China; taowang81@sina.com (W.T.); leizhenglong@hit.edu.cn (Z.L.) \\ 2 Harbin HIT Weld Technology Co., Ltd., Harbin 150060, China; yangzhaohuiworld@126.com \\ 3 Harbin FRP Research Institute, Harbin 150036, China; nantiantian1020@126.com \\ * Correspondence: tangyuan-888@163.com (Y.Z.); chenyb@hit.edu.cn (Y.C.); Tel.: +86-451-8641-8645 (Y.C.)
}

Received: 21 November 2019; Accepted: 4 December 2019; Published: 6 December 2019

\begin{abstract}
The durable structure and robustness of T-joints in the panel materials for civil aircraft are a crucial matter of importance. In this work, the impact of the post-weld heat treatments (PWHTs) on the microstructure and mechanical properties of laser beam welded T-joints of 2060-T3/2099-T3 Al-Li alloy was analyzed. Heat-treatment of the laser beam welded T-joints was carried out in two different ways, namely, solution treatment and artificial aging (STAA) at varied duration and only artificial aging (AA) at varied duration. The microstructure and mechanical properties of the heat-treated joints were investigated using metallographic and scanning electron microscopic images, micro-hardness test, and tensile test, respectively. The results showed that, in cases of STAA, the eutectic structures on the grain boundary were partially dissolved via solution treatment (ST), and increased dispersed precipitation of the second phase in matrix resulted in significant dispersion strengthening, as well as enhanced strength and plasticity. In contrast, in the AA process, alloy elements in the matrix continued to segregate towards the grain boundary, resulting in significant grain boundary strengthening, enhanced strength, and decreased plasticity. Additionally, joint fractures were micro-porous aggregation transgranular ones in the fusion zone (FZ). The joints treated by STAA exhibited excellent plasticity compared with those treated by AA. Furthermore, the micro-hardness of welded joints treated by AA was higher than that of those treated by STAA. Indeed, the tensile strength of joints treated by STAA and AA ranged from 405 to $475 \mathrm{MPa}$, which was $81-95 \%$ of the base metal 2060-T8, though the elongation of joints treated by STAA was superior to the counterpart AA.
\end{abstract}

Keywords: laser beam welding; post-weld heat treatment; Al-Li alloys; microstructure; mechanical properties

\section{Introduction}

Compared with traditional aluminum alloy, Al-Cu-Li alloy is highly promising for applications in the aerospace industry owing to its low density, high elasticity module, high specific stiffness, and high specific strength [1-4], and 2060/2099 Al-Li alloys are one of the alloys in the Al-Cu-Li alloy system. For each $1 \% \mathrm{Li}$ added, the density of the aluminum alloy is reduced by $3 \%$ and the elastic modulus is increased by 6\% [1,2]. The Al-Li alloys 2090 and 2091 contain 1.9-2.6\% lithium, which leads to an about $10 \%$ lower density and $25 \%$ higher specific stiffness than the 2 XXX and 7 XXX series aluminum alloys [3]. Importantly, Al-Li alloys, especially those consisting of volatile metal elements such as $\mathrm{Li}$ and $\mathrm{Mg}$, are readily exposed to solidification cracking and pore defects during fusion welding, resulting in poor weld formation [5-8]. The evaporation of low boiling point alloy elements and the 
instability of the keyhole tip are the main reasons for large, irregular-shaped pores [5,6]. The trapping of hydrogen bubbles as the welding pool solidified is the main cause of micro porosity in laser welding of Al-Li alloy [7,8]. During the welding process, the strength of the original welding materials would be softened in the fusion zone (FZ) [9-13]. Ramulu et al. [9] employed tungsten inert gas arc to weld $2090 \mathrm{Al}-\mathrm{Li}$ alloy and demonstrated that the strength of joints welded by wires such as 2319/4047/4145 reached up to $60.3 \%$ of the strength of the base metal. Also, the maximum strength coefficients of the laser beam welded $2060 \mathrm{Al}-\mathrm{Li}$ alloy joint with Al-Mg filler wire [10] and the laser beam welded 2198 Al-Li alloy joint with Al-Si filler wire [11] were 0.63 and 0.65, respectively. The lack of strengthening precipitates related to the matrix precipitation hardening was considered to be the main reason for the hardness/strength reduction in the FZ $[12,13]$. Ongoing research in this area showed that, compared with traditional fusion welding, a high-energy beam welding can improve the joint strength, which can be further improved by post-weld heat treatment. Ben et al. [14] performed a $24 \mathrm{~h}$ post-weld solid treatment (salt bath at $535^{\circ} \mathrm{C}$ for $30 \mathrm{~min}$ ) and AA at $165^{\circ} \mathrm{C}$ for $24 \mathrm{~h}$ for Al-Cu-Li alloy based joints welded by the electron beam. Specifically, the microstructure of the central FZ was transformed from dendrite crystals to equiaxed crystals. The segregation on the grain boundary was eliminated, and the coefficient of strength was increased from 0.60 to 0.85 . Zhuang et al. [15] reported laser beam welding of $1420 \mathrm{Al}-\mathrm{Li}$ alloy and achieved joint strength of $75 \%$ of that of the base metal. It should be noted that after solid treatment at $460^{\circ} \mathrm{C}$ followed by AA at $120^{\circ} \mathrm{C}$ for $10 \mathrm{~h}$, the tensile strength of the joint increased to $96 \%$ of that of the base metal. So far, the laser beam welding of 2060-T3/2099-T3 Al-Li alloy based T-joints and related scientific testing data are rarely reported $[16,17]$. In this study, laser beam welding was used for 2060-T3/2099-T3 Al-Li alloy based T-joints. After welding, two different heat treatments, namely, solution treatment and artificial aging (STAA), and artificial ageing (AA), of the welded T-joints were carried out. STAA was a combination of the solution treatment at $500^{\circ} \mathrm{C}$ for $1 \mathrm{~h}$ afterward artificial aging at $165^{\circ} \mathrm{C}$ for the duration of $10 \mathrm{~h}, 20 \mathrm{~h}$, and $30 \mathrm{~h}$. In contrast, AA at $165^{\circ} \mathrm{C}$ for $10 \mathrm{~h}, 20 \mathrm{~h}$, and $30 \mathrm{~h}$ was carried after the laser beam welding. Afterwards, the microstructures and mechanical properties of joints treated by STAA and AA were investigated and a comparative analysis was done to understand the impact of post-weld heat treatment on the performance of laser beam welded Al-Li alloyed T-joints. Thus, this scientific work would provide insight into technical support for laser beam welding of Al-Li alloys.

\section{Materials and Methods}

The testing material used was the commercially available panel material for civil aircraft fuselage. The skin material and the stringer material were 2060-T3Al-Li alloy rolled sheet and extruded 2099-T3Al-Li alloy, respectively. The dimension specifications of the rolled sheet of skin and stringer material were $400 \mathrm{~mm}$ (length) $\times 130 \mathrm{~mm}$ (width) $\times 1.5 \mathrm{~mm}$ (thickness) and $400 \mathrm{~mm}$ (length) $\times 2.0 \mathrm{~mm}$ (thickness), respectively. The filler wire was ER4047 wire with a diameter of $1.2 \mathrm{~mm}$ and related chemical compositions of the base metal 2060-T8 and filler wire are shown in Table 1. Before testing, $\mathrm{NaOH}$ was utilized to remove oxide films from the test materials, followed by neutralization by acid $\mathrm{HNO}_{3}$, and then washed by clean water and dried well.

The applied welding method was double-sided laser synchronous welding (fiber laser $=$ YLS-5000 and YLS-10000, IPG photonics corp., Germany). Protecting gas nozzles and wire feeding devices (wire-feeder $=\mathrm{KD}-4010$, Frontius International $\mathrm{GmbH}$, Austria) were arranged on both sides at an appropriate angle to each other. The welding equipment was fixed on the two six-axis robot arms (KR-16W, KUKA Robot Group, Germany) and the stringer was vertically pressed on the skin by an assembly technology clamp. The laser beam, the wire-feeder, and the protecting gas nozzle were located on the same plane. The angle $(\alpha)$ between the laser beam and skin was fixed at $22^{\circ}$, the angle $(\beta)$ between the wire-feeder and the welding direction and the angle $(\theta)$ between the protecting gas nozzle and the welding direction were fixed at $20^{\circ}$ each. As shown in Figure 1, the wire-feeder and the protecting gas nozzle were positioned at either side beyond the end of the welding site, respectively. The direction of welding and the plate rolling was consistent during the welding process. 
A large number of welding process tests of laser-welded 2060-T8 and 2099-T83 Al-Li alloy T-joints had been carried out to explore and optimize process parameters in the early stage [17]. In this research, the same welding system was applied and several test specimens were welded with different welding process parameters (i.e., laser power and wire feeding rate). The welding process parameters were optimized as shown in Table 2 and four of the test specimens under the same welding process parameters were selected for post-weld heat treatment (PWHT) and subsequent tests. The selected standard was that the weld was well formed and no pores or cracks were formed on the welding surface, as shown in Figure 2.

Table 1. Chemical compositions of the base metal and the filler wire (wt.\%).

\begin{tabular}{ccccccccccc}
\hline Materials & $\mathbf{C u}$ & $\mathbf{L i}$ & $\mathbf{S i}$ & $\mathbf{M g}$ & $\mathbf{Z n}$ & $\mathbf{M n}$ & $\mathbf{Z r}$ & $\mathbf{A g}$ & $\mathbf{F e}$ & $\mathbf{A l}$ \\
\hline $2060-\mathrm{T} 3$ & 3.90 & 0.80 & 0.02 & 0.70 & 0.32 & 0.29 & 0.10 & 0.34 & 0.02 & Bal. \\
$2099-\mathrm{T} 3$ & 2.52 & 1.87 & - & 0.50 & 1.19 & 0.31 & 0.08 & - & - & Bal. \\
ER4047 & $<0.001$ & - & 11.52 & 0.01 & 0.001 & 0.01 & - & - & 0.20 & Bal. \\
\hline
\end{tabular}

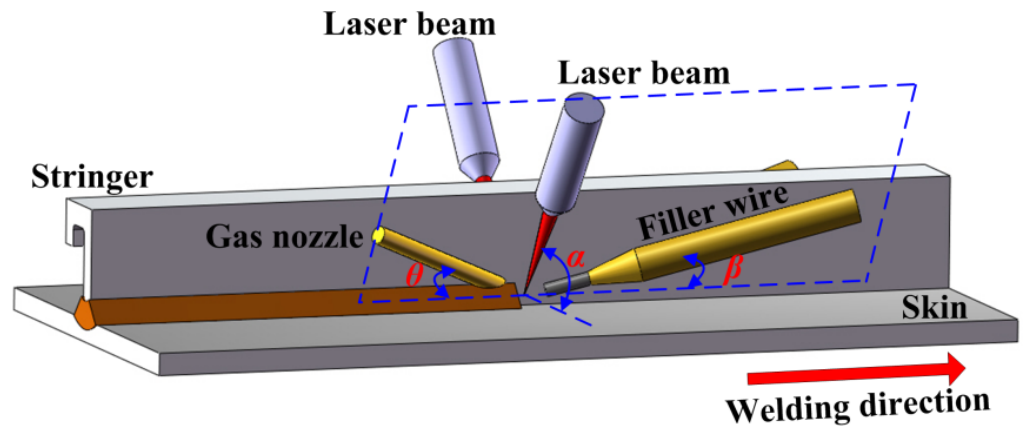

Figure 1. Schematic of the laser beam welding.

Table 2. Parameters of laser beam welding.

\begin{tabular}{cc}
\hline Welding Parameters & Values \\
\hline Laser power $(\mathrm{P})$ & $2800 \mathrm{~W}$ \\
Welding speed $(\mathrm{v})$ & $10 \mathrm{~m} / \mathrm{min}$ \\
Wire feeding rate $\left(\mathrm{v}^{\prime}\right)$ & $3.6 \mathrm{~m} / \mathrm{min}$ \\
Incident beam angle $(\alpha)$ & $22^{\circ}$ \\
Wire feeding angle $(\beta)$ & $20^{\circ}$ \\
Protecting gas angle $(\theta)$ & $20^{\circ}$ \\
Focal position & Specimen surface \\
Protecting gas & $\mathrm{Ar}$ \\
Protecting gas flow rate & $15 \mathrm{~L} / \mathrm{min}$ \\
\hline
\end{tabular}
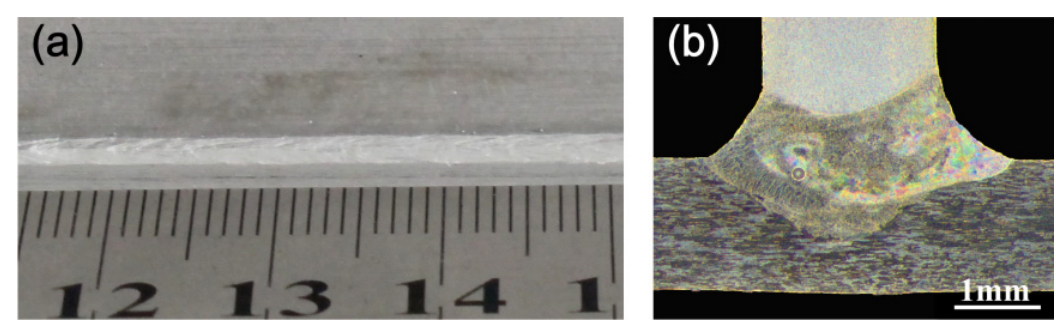

Figure 2. The photographs of the T-joint: (a) one-sided weld surface appearance and (b) metallographic photograph at the cross-section of the T-joint. 
Before welding, the testing material was at the T3 heat treatment state and could not be used without post-weld heat treatment. The strength of the T-joints after post-weld heat treatments was compared with that of the base metal 2060-T8 (501 MPa tensile strength), which can be directly used in the riveted structure of the aircraft fuselage. The incorporated two different post-weld heat treatment process were as follows: first as STAA: post-weld ST at $500^{\circ} \mathrm{C}$ for $1 \mathrm{~h}$ followed by water cooling up to room temperature, and thereafter the AA process at $165^{\circ} \mathrm{C}$ for the varying duration of $10 \mathrm{~h}, 20 \mathrm{~h}$, and $30 \mathrm{~h}$, followed by natural cooling up to room temperature in the furnace; second as AA: post-weld AA process at $165^{\circ} \mathrm{C}$ for $10 \mathrm{~h}, 20 \mathrm{~h}$, and $30 \mathrm{~h}$, followed by natural cooling up to room temperature in the furnace. The process parameters of AA in these two methods were consistent. The process parameters of PWHT and the number of samples for tests under these PWHT parameters are shown in Table 3. The sample for metallographic inspection was first sanded and then polished nicely. Also, a corrosion-free cleaning in the Keller's reagent (configuration ratio: $1 \mathrm{~mL} \mathrm{HF}, 1.5 \mathrm{~mL} \mathrm{HCl}, 2.5 \mathrm{~mL}$ $\mathrm{HNO}_{3}, 95 \mathrm{~mL}$ water) for $20 \mathrm{~s}$ was done before it underwent testing. The microstructures of the welded joints and joints after post-weld heat treatment were investigated using optical microscope (OLYMPUS-GX71, Japan) and scanning electron microscope (SEM, FEI Quanta 200FEG, America). Further, a micro-hardness test and tensile test were performed on these T-joints after post-weld heat treatments. The micro-hardness test and the tensile test were done using a Vickers micro-hardness meter (HXD-1000TM, China) with a $200 \mathrm{~g}$ load for $10 \mathrm{~s}$ and an electronic universal testing machine (INSTRON-5569, America), respectively. The specimens for the tensile test were prepared using ASTM E $8 \mathrm{M}-04$ and the tensile rate was $2 \mathrm{~mm} / \mathrm{min}$ throughout the testing. Figure 3 shows the dimensions of tensile samples. In this work, for each heat treatment parameter, three samples were involved for the tensile test and the average of these values was considered as the tensile strength of a particular one.

Table 3. Process parameters of post-weld heat treatment (PWHT). ST, solution treatment; AA, artificial aging; SEM, scanning electron microscope.

\begin{tabular}{cccc}
\hline & PWHT & Number of Samples & \\
\cline { 3 - 4 } No. & & $\begin{array}{c}\text { Metallographic Inspection, SEM } \\
\text { Observation, and Micro-Hardness Test }\end{array}$ & $\begin{array}{c}\text { Tensile } \\
\text { Test }\end{array}$ \\
\hline $1-1$ & $\mathrm{ST}$ at $500{ }^{\circ} \mathrm{C}$ for $1 \mathrm{~h}$ and $\mathrm{AA}$ at $165^{\circ} \mathrm{C}$ for $10 \mathrm{~h}$ & 2 & 3 \\
$1-2$ & $\mathrm{ST}$ at $500{ }^{\circ} \mathrm{C}$ for $1 \mathrm{~h}$ and $\mathrm{AA}$ at $165^{\circ} \mathrm{C}$ for $20 \mathrm{~h}$ & 2 & 3 \\
$1-3$ & $\mathrm{ST}$ at $500{ }^{\circ} \mathrm{C}$ for $1 \mathrm{~h}$ and $\mathrm{AA}$ at $165^{\circ} \mathrm{C}$ for $30 \mathrm{~h}$ & 2 & 3 \\
$2-1$ & AA at $165^{\circ} \mathrm{C}$ for $10 \mathrm{~h}$ & 2 & 3 \\
$2-2$ & AA at $165^{\circ} \mathrm{C}$ for $20 \mathrm{~h}$ & 2 & 3 \\
$2-3$ & AA at $165^{\circ} \mathrm{C}$ for $30 \mathrm{~h}$ & 2 & 3 \\
\hline
\end{tabular}

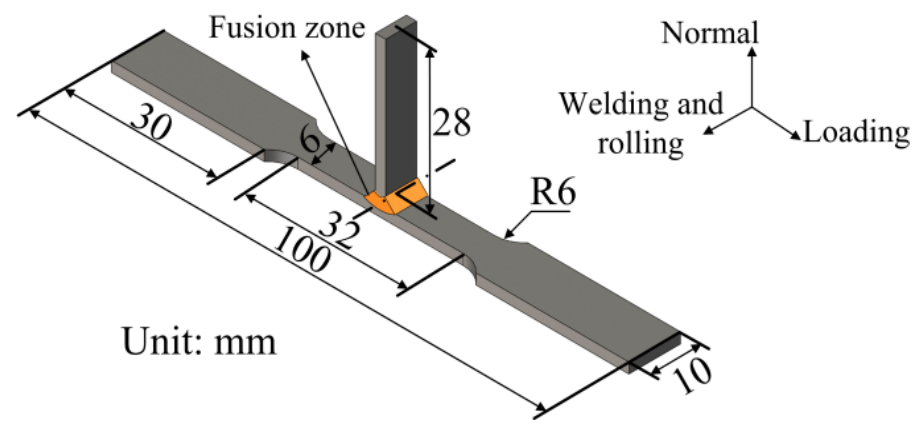

Figure 3. Dimensions of tensile samples.

\section{Results and Discussion}

In this section, tensile strength, micro-hardness, and microstructure of the welded T-joints produced under the different parameter will be studied to optimize the post-weld heat treatment method. The tensile fracture, micro-hardness, and microstructure of the welded T-joints heat-treated 
by STAA $\left(165^{\circ} \mathrm{C}\right.$ for $\left.20 \mathrm{~h}\right)$ and AA $\left(165^{\circ} \mathrm{C}\right.$ for $\left.20 \mathrm{~h}\right)$ were recorded for a comparable analysis of the joint strengthening effects, which was caused by the heat treatment of STAA and AA, distinctively.

\subsection{Effects of Post-Weld Heat Treatment on Tensile Properties}

The tensile strength and elongation of the T-joints produced under different heat treatment parameters are shown in Table 4. The trend of the tensile strength as a function of aging period is shown in Figure 4. The stress-strain curves of the T-joints treated by STAA and AA at different conditions of heat treatment, respectively, are shown in Figure 5. The STAA treated samples exhibited the increased tensile strength and slightly decreased elongation as the aging period was increased. Thus, the joints heat-treated by STAA did not reach the overaged condition. On the other side, the tensile strength was increased initially and then a decrement was noticed in the joints heat-treated by AA. The joint heat-treated by AA demonstrated the under aged, peak-aged, and overaged conditions. The strength coefficient of the welded T-joints under four different heat treatment parameters, namely, STAA at $165^{\circ} \mathrm{C}$ for $20 \mathrm{~h}$, STAA at $165^{\circ} \mathrm{C}$ for $30 \mathrm{~h}$, AA at $165^{\circ} \mathrm{C}$ for $20 \mathrm{~h}$, and AA at $165^{\circ} \mathrm{C}$ for $30 \mathrm{~h}$, exceeded $80 \%$, which satisfies the strength requirement for the purpose of industrial applications. Notably, joints treated by AA alone exhibited elongations less than $1 \%$, while the ductility of the joints after solution treatment was considerably higher than that before the treatment. In terms of the mechanical properties like strength and toughness, the welded T-joints were treated by two heat treatments, namely, STAA at $165^{\circ} \mathrm{C}$ for $20 \mathrm{~h}$ and STAA at $165^{\circ} \mathrm{C}$ for $30 \mathrm{~h}$, which are preferably suitable for industrial applications.

Table 4. Tensile strengths, strength coefficients, and elongations of joints under different heat treatment parameters.

\begin{tabular}{|c|c|c|c|}
\hline PWHT & Tensile Strength & Strength Coefficient * & Elongation \\
\hline ST at $500^{\circ} \mathrm{C}$ for $1 \mathrm{~h}$ and $\mathrm{AA}$ at $165^{\circ} \mathrm{C}$ for $10 \mathrm{~h}$ & $370 \mathrm{MPa}$ & $74 \%$ & $11-13 \%$ \\
\hline ST at $500^{\circ} \mathrm{C}$ for $1 \mathrm{~h}$ and $\mathrm{AA}$ at $165^{\circ} \mathrm{C}$ for $20 \mathrm{~h}$ & $405 \mathrm{MPa}$ & $81 \%$ & $5-8 \%$ \\
\hline ST at $500^{\circ} \mathrm{C}$ for $1 \mathrm{~h}$ and $\mathrm{AA}$ at $165^{\circ} \mathrm{C}$ for $30 \mathrm{~h}$ & $421 \mathrm{MPa}$ & $85 \%$ & $2-5 \%$ \\
\hline $\mathrm{AA}$ at $165^{\circ} \mathrm{C}$ for $10 \mathrm{~h}$ & $390 \mathrm{MPa}$ & $78 \%$ & $<1 \%$ \\
\hline $\mathrm{AA}$ at $165^{\circ} \mathrm{C}$ for $20 \mathrm{~h}$ & $475 \mathrm{MPa}$ & $95 \%$ & $<1 \%$ \\
\hline $\mathrm{AA}$ at $165^{\circ} \mathrm{C}$ for $30 \mathrm{~h}$ & $470 \mathrm{MPa}$ & $94 \%$ & $<1 \%$ \\
\hline
\end{tabular}

* Strength coefficient is the ratio between the tensile strength of the joint and that of the 2060-T8 base metal.

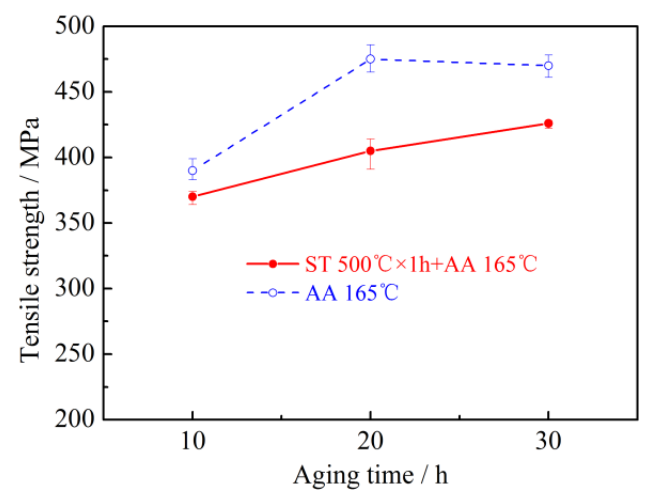

Figure 4. Trends of tensile strength as a function of aging time. ST, solution treatment; AA, artificial aging. 


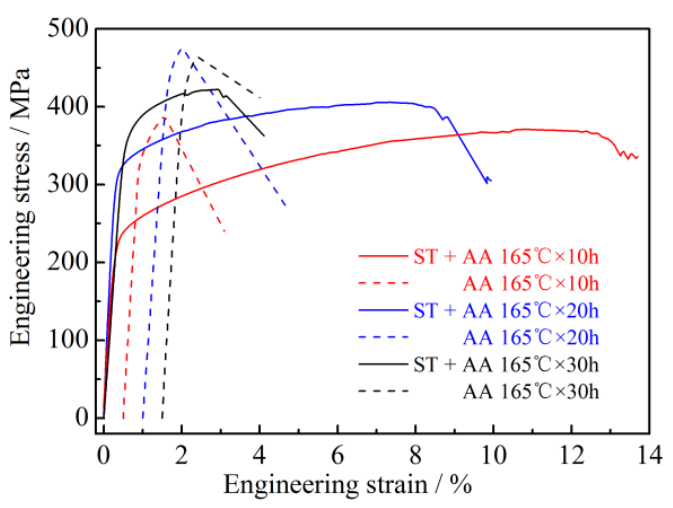

Figure 5. Engineering stress-strain curve.

Figure 6 illustrates the fractured surface of the welded T-joints treated by STAA at $165{ }^{\circ} \mathrm{C}$ for $20 \mathrm{~h}$ and $\mathrm{AA}$ at $165^{\circ} \mathrm{C}$ for $20 \mathrm{~h}$. As can be seen, fractures in all the samples occurred firstly near the skin side in the FZ, which is considered the weak area of the welded joint. Additionally, various dimples were observed on the fractured section, which also consisted of the second phase particles or related traces. Hence, fractures were transgranular ones with micro-porous aggregation. It should be noted that the dimples on the fractured joints that were heat-treated by STAA at $165{ }^{\circ} \mathrm{C}$ for $20 \mathrm{~h}$ exhibited large depth and size, and thus an excellent demonstration of plasticity in the both microscopic and macroscopic aspects.
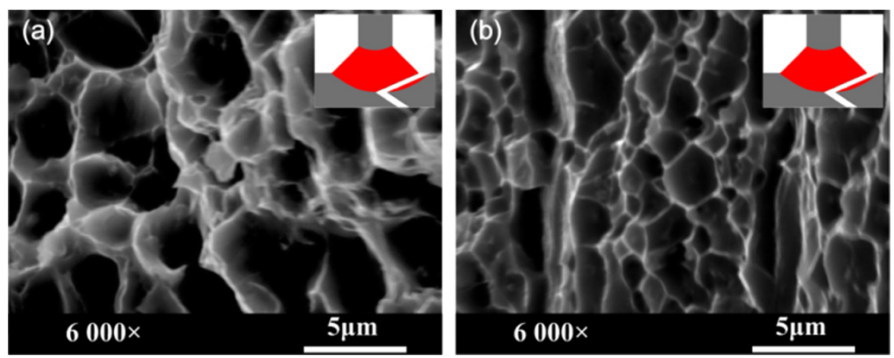

Figure 6. Tensile fracture morphology of the fusion zone (FZ) for the joints treated by (a) STAA at $165^{\circ} \mathrm{C}$ for $20 \mathrm{~h}$ and (b) AA at $165^{\circ} \mathrm{C}$ for $20 \mathrm{~h}$.

\subsection{Effects of Post-Weld Heat Treatment on Micro-Hardness}

Micro-hardness analysis was performed on the metallographic cross-sections of the heat-treated by STAA at $165^{\circ} \mathrm{C}$ for $20 \mathrm{~h}$ and AA at $165^{\circ} \mathrm{C}$ for $20 \mathrm{~h}$ welded T-joints, respectively. The testing sites were arranged on the stringer, upper fusion boundary (FB), central FZ, lower FB, and skin, as can be seen in Figure 7. The results demonstrated that the average micro-hardness of the welded T-joints heat-treated by STAA was achieved as $119.2 \mathrm{HV}, 144.6 \mathrm{HV}$, and $109.3 \mathrm{HV}$ at the central FZ, skin, and stringer, respectively. On the similar testing sites, the average micro-hardness was achieved as $134.2 \mathrm{HV}$, $169.5 \mathrm{HV}$, and 160.2 HV in the counterpart AA heat-treated joints, respectively. The micro-hardness of joints treated by AA exceeded that of joints treated by STAA. It is worth noting that the Al-Li alloy 2060/2099 is a typical precipitate strengthened alloy [16,17], and laser beam welding consists of rapid heating and cooling, which leaves insufficient time for precipitation of alloy elements in the FZ [18]. As a result, the generation of precipitation phases was reduced compared with that of the base materials and the FZ remained in an under aged condition, resulting in ineffective aging strengthening and reduced micro-hardness at the FZ [18]. Therefore, the micro-hardness of the heat-affected zone (HAZ) degraded as a consequence of AA. The enhancement of the micro-hardness of joints treated by post-weld heat treatment can be attributed to the microstructure transition caused by AA, which will be discussed in the following sections. The micro-hardness of the joint treated by STAA was larger 
than that of the joint treated by AA. For the STAA and AA methods, the aging temperature and time were identical, but STAA included the solution treatment. This can be attributed to the fact that a small amount of precipitation phases, such as the $\mathrm{Al}_{2} \mathrm{Cu}$ phase [19] in the $\mathrm{FZ}$, and a part of precipitation phases, such as the $\mathrm{Al}_{7} \mathrm{Cu}_{4} \mathrm{Li}$ phase [20] in the HAZ, were re-dissolved into the matrix, which were induced by solution treatment.

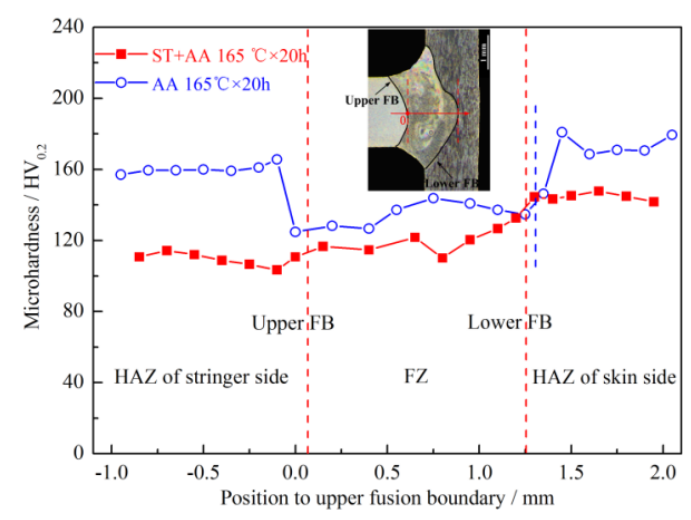

Figure 7. Micro-hardness distribution. HAZ, heat-affected zone; FB, fusion boundary; FZ, fusion zone.

\subsection{Effects of Post-Weld Heat Treatment on Joint Microstructures}

Figure 8 shows the metallographic structure of the parts that are near to the lower FB of the 2060-T3/2099-T3 Al-Li alloy T-joints heat-treated by STAA at $165^{\circ} \mathrm{C}$ for $20 \mathrm{~h}$ and AA at $165^{\circ} \mathrm{C}$ for $20 \mathrm{~h}$, respectively. As shown in Figure $8 \mathrm{a}$, the microstructure of laser beam welded joints can be divided into the base metal, HAZ, partially melted zone (PMZ), equiaxed zone (EQZ), and FZ. Owing to the melting and solidification of the grain boundary with a low melting point inside the PMZ during the welding, alloy elements at the grain boundary are more prone to segregation and aggregation as compared with those in grains. That is why the grain boundaries were more susceptible to corrosion by Keller's reagent and also appeared in the metallographic picture. The EQZ is a unique microstructure of the Al-Li alloy welded joint. First, nuclei formation was triggered in the fine-grain region with high melting point particles of $\mathrm{Al} 3 \mathrm{Zr}$ as the nuclei, resulting in fine microstructures. The thickness of the fine-grain zone was about $20 \mu \mathrm{m}$. In FZ, the crystallization rate, size of the constitutional undercooled zone, and nucleation speed were decreased as the temperature of the molten pool was increased. Then, the growth of the metal at the molten pool around EQZ was limited along the direction that is perpendicular to the wall of the molten pool. Also, the fastest heat dissipation rate assisted the formation of the dendrite structure in FZ as a consequence of segregation of alloy elements. As shown in Figure 8b, the lower FB, FZ dendrite structure, PMZ, and EQZ were removed after solution treatment. This can be attributed to the solid solution of alloy elements in the FZ dendrite structure and segregated alloy elements on PMZ and EQZ grain boundary into the matrix after solution treatment. As shown in Figure $8 \mathrm{c}$, the lower FB of the joint and the dendrite structure of FZ, PMZ, and EQZ were observed under a low-resolution microscope. In other words, the microstructure in this case was consistent with that at the welding state.
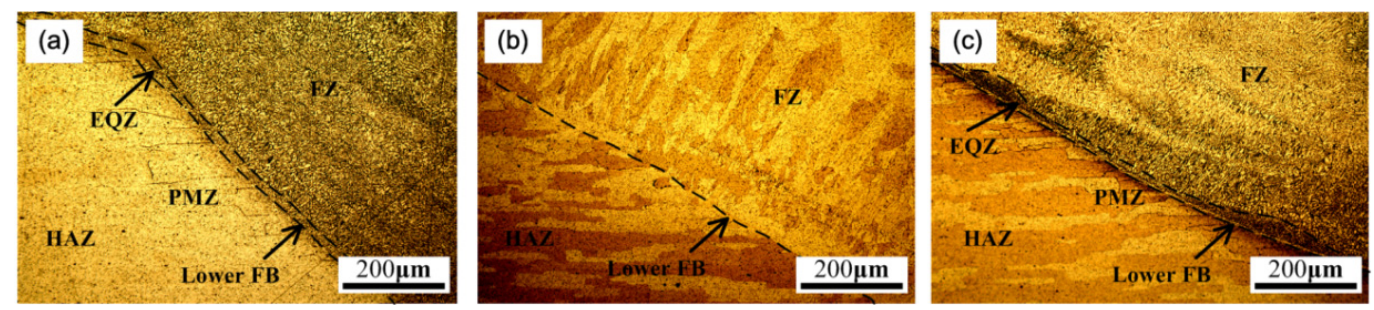

Figure 8. Metallographic structure near the lower FB of Al-Li alloy T-joints: (a) welding state, (b) STAA at $165{ }^{\circ} \mathrm{C}$ for $20 \mathrm{~h}$, and (c) AA at $165^{\circ} \mathrm{C}$ for $20 \mathrm{~h}$. PMZ, partially melted zone; EQZ, equiaxed zone. 
The micro-hardness of the FZ was lower than that of the heat-affected zone on the skin side. The section of the tensile fracture was close to the lower FB in the FZ. Hence, microstructure of the FZ was investigated carefully. Backscatter electron (BSE) scanning and energy spectrum analysis were performed on the T-joints to analyze the effects of the post-weld heat treatment on the FZ. Figure 9 shows BSE images of microstructure of the FZ before and after post-weld heat treatment. Table 5 shows the mass fraction and atomic fraction of alloy elements. As can be seen in Figure 9a, at the different positions, there are no traces of $\mathrm{Si}$ in the base metal, while the primary alloy element of the filler wire was Si. According to energy spectra of P1, P2, and P3, black and white phases mainly contain Si and $\mathrm{Cu}$, respectively. Specifically, the grain strengthening phases in the FZ were mainly composed of the $\mathrm{T}$ phase with fiber-like distribution (AlLiSi, black phase in BSE image), the Cu-contained eutectic phases (white phase in BSE image), and some dispersed precipitated phases [17].

As shown in Figure 9b, for the welded joints heat-treated by STAA, the Cu-contained eutectic phases at grain boundary disappeared; however, $\mathrm{T}$ phases were grown into spheroidized form at the grain boundary. It transformed the distribution of grain boundary from a continuous phase to a discontinuous one. The dispersed precipitation of the second phase from the matrix was increased. From the macroscopic aspect, the distribution of strengthening phases in the FZ changed from a continuous one to a dispersed one, resulting into enhanced dispersion strengthening and reduced grain boundary strengthening. This is mainly attributed to the acceleration of atomic diffusion by solution treatment, resulted in diffusion of alloy elements at the grain boundary to the matrix, homogenization of the matrix, elimination of composition segregation of the dendrite crystals, and generation of supersaturated solid solutions. Further, AA after solution treatment induces the precipitation decomposition of the supersaturated solid-solution and re-dispersion and/or re-precipitation of alloy elements in the FZ from the super-satisfied solution as second phase particles. It enhanced the dispersion strengthening, substantially strength, hardness, and plasticity of the welded T-joints.

As shown in Figure 9c, for the welded joints heat-treated by AA, T phases, and Cu-contained eutectic phase at grain boundary were coarse owing to the absence of solution treatment assisted diffusion of alloy elements to the matrix. It initiated the diffusion of alloy elements from the matrix phase to the grain boundary, resulting in reduced dispersion strengthening and enhanced grain boundary strengthening. This is attributed to the fact that AA heat treatment after laser beam welding stimulates the continuous segregation of alloy elements in the FZ towards the grain boundary of the dendrite crystals. The severe segregations at the grain boundary lead to the continuous, coarse, and dense grain boundary, and thus enhanced grain boundary strengthening, improved strength, and hardness of the joint, as well as reduced plasticity of the joint, have resulted.
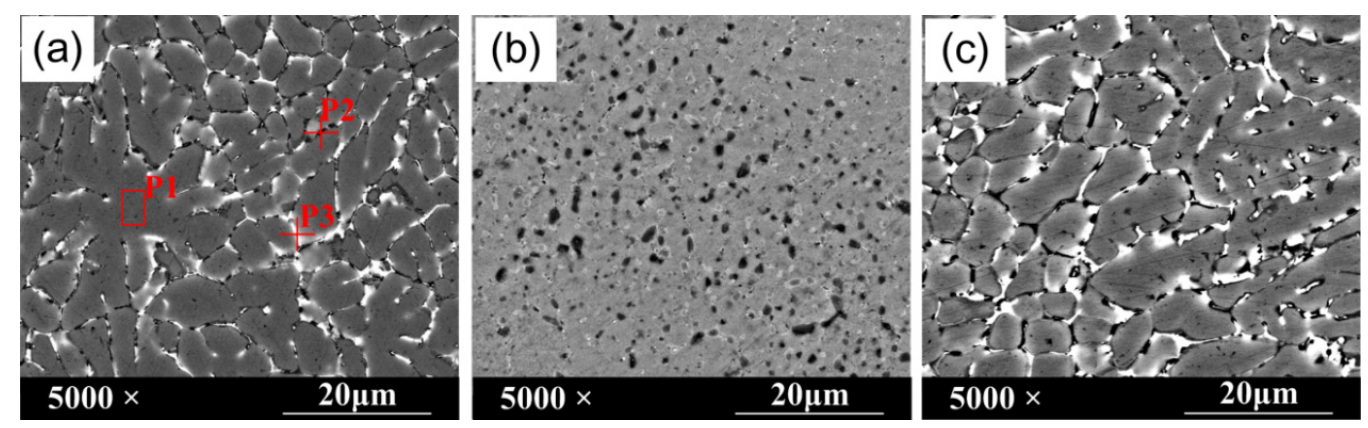

Figure 9. Backscatter electron (BSE) image of the FZ for Al-Li alloy T-joints: (a) welding state, (b) STAA at $165^{\circ} \mathrm{C}$ for $20 \mathrm{~h}$, and (c) AA at $165^{\circ} \mathrm{C}$ for $20 \mathrm{~h}$. 
Table 5. Mass fractions and atomic fractions of alloy elements in different positions of the fusion zone (FZ).

\begin{tabular}{cccccccccc}
\hline \multirow{2}{*}{ Element } & \multicolumn{2}{c}{ Cu } & \multicolumn{2}{c}{ Si } & \multicolumn{2}{c}{ Mg } & \multicolumn{2}{c}{ Al } \\
\cline { 2 - 10 } & wt.\% & at.\% & wt.\% & at.\% & wt. $\%$ & at.\% & wt.\% & at.\% \\
\hline P1 & 2.60 & 1.10 & 1.54 & 1.51 & 1.02 & 1.16 & 94.84 & 96.23 \\
P2 & 2.03 & 0.88 & 13.66 & 13.38 & 0.81 & 0.93 & 83.50 & 84.82 \\
P3 & 11.64 & 5.29 & 0.68 & 0.70 & 1.72 & 2.07 & 85.96 & 91.94 \\
\hline
\end{tabular}

\section{Conclusions}

In summary, laser beam welded 2060-T3/2099-T3 Al-Li alloy based T-joints were heat-treated by STAA and AA after welding at various process parameters. The results demonstrated that the tensile strengths of joints treated by STAA at $165^{\circ} \mathrm{C}$ for $20 \mathrm{~h}$ and $30 \mathrm{~h}$ and AA after welding at $165^{\circ} \mathrm{C}$ for $20 \mathrm{~h}$ and $30 \mathrm{~h}$ were $405-475 \mathrm{MPa}$, which is $81-95 \%$ of the strength of the base metal 2060 -T8. The elongations of joints heat-treated by STAA were superior to those treated by AA. The enhanced performance of T-joints after STAA was analyzed from the perspective of microstructure. The results demonstrated that the distribution of the strengthening phases at the grain boundary changed from a continuous one to a dispersed one. The eutectic structures on the grain boundary were partially spheroidized and partially dissolved in the matrix via solution treatment. Although dispersed precipitation of the second phase from the matrix was increased, it resulted in significant dispersion strengthening and enhanced strength and plasticity. In the AA process, segregation of the alloy elements in the FZ of matrix to grain boundary was continued. The strengthening phases on the grain boundary were continuous, coarse, and dense, which resulted in enhanced grain boundary strengthening, and thus improved strength and decreased plasticity. The post-weld STAA treatment $\left(\right.$ ST $500^{\circ} \mathrm{C} \times 1 \mathrm{~h}+\mathrm{AA} 165^{\circ} \mathrm{C} \times 20 \mathrm{~h}$ or $30 \mathrm{~h}$ ) is an efficient and optimized condition to improve the strength and toughness of 2060-T3/2099-T3 Al-Li alloy based T-joints. This approach can be used to enhance the overall performances of the T-joints for industrial application.

Author Contributions: Conceptualization, Y.C. and W.T.; formal analysis, Y.Z.; investigation, Y.Z. and Y.C.; resources, Y.C. and W.T.; data curation, Y.Z.; writing-original draft preparation, Y.Z. and T.N.; writing-review and editing, Y.C. and W.T.; visualization, Y.Z.; supervision, Y.C. and W.T.; project administration, Y.C., W.T., and Z.L.; funding acquisition, Y.C. and Z.Y.

Funding: This research was funded by the National Key Research and Development Program of China, grant number No.2017YFB1301600.

Acknowledgments: The authors would like to gratefully acknowledge the National Engineering Research Center of Commercial Aircraft Manufacturing for providing the Al-Li alloys that would be used in fuselage panels.

Conflicts of Interest: No conflict of interest exists in the submission of this manuscript, and the manuscript is approved by all authors for publication. All authors would like to declare that none of the material in the paper has been published or is under consideration for publication elsewhere.

\section{References}

1. Polmear, I.J. Aluminum alloys-A century of age hardening. Mater. Forum 2004, 28, 1-14.

2. Roberto, J.R. Fabrication methods to manufacture isotropic Al-Li alloys and products for space and aerospace applications. Mater. Sci. Eng. A 1998, 257, 100-107.

3. Dursun, T.; Soutis, C. Recent developments in advanced aircraft aluminum alloys. Mater. Des. 2014, 56, 862-871. [CrossRef]

4. Gupta, R.K.; Nayanb, N.; Nagasireesha, G.; Sharma, S.C. Development and characterization of Al-Li alloys. Mater. Sci. Eng. A 2006, 420, 228-234. [CrossRef]

5. Wang, W.; Xu, G.Y.; Duan, A.Q.; Wang, X.Y.; Ba, R.Z. Porosity formation mechanism in laser welding 1420 Al-Li alloy. Trans. China Weld. Inst. 2005, 26, 59-62.

6. Xiao, R.S.; Yang, W.X.; Chen, K. Nd: YAG laser welding of 1420 aluminum-lithium alloy. Chin. J. Lasers 2007, 34, 239-241. 
7. Canaby, J.L.; Blazy, F.; Fries, J.F.; Traverse, J.P. Effects of high temperature surface reactions of aluminum-lithium alloy on the porosity of welded areas. Mater. Sci. Eng. A 1991, 136, 131-139. [CrossRef]

8. Huang, M.; Li, G.A.; Zhang, K.; Feng, Z.H. Laser welding characteristics of 2A97 Al-Li alloy. Trans. China Weld. Inst. 2014, 35, 100-104.

9. Ramulu, M.; Rubbert, M.P. Gas tungsten arc welding of Al-Li-Cu alloy 2090. Weld. Res. Suppl. 1990, 109s-114s.

10. Zhang, X.Y.; Yang, W.X.; Xiao, R.S. Microstructure and mechanical properties of laser beam welded Al-Li alloy 2060 with Al-Mg filler wire. Mater. Des. 2015, 88, 446-450. [CrossRef]

11. Lin, K.L.; Yang, W.X.; Lv, J.X.; Xiao, R.S. Laser beam welding study of 2198-T851 aluminum-lithium alloy. Chin. J. Lasers 2014, 41. [CrossRef]

12. Zhang, X.Y.; Huang, T.; Yang, W.X.; Xiao, R.S.; Liu, Z.; Li, L. Microstructure and mechanical properties of laser beam-weldedAA2060 Al-Li alloy. J. Mater. Process. Technol. 2016, 237, 301-308. [CrossRef]

13. Cao, X.; Wallace, W.; Immarigeon, J.P.; Poon, C. Research and progress in laser welding of wrought aluminum alloys. II. metallurgical microstructures, defects, and mechanical properties. Mater. Manuf. Processes 2003, 18, 23-49. [CrossRef]

14. Ben, H.F. Electron Beam Welding Technology of Al-Cu-Li Alloy and Microstructure and Properties of Welded Joint. Master's Thesis, Nanjing University of Aeronautics and Astronautics, Nanjing, China, 2015.

15. Zhuang, L. Research on the Micro Structures and Properties of Laser Welding Joint for 1420 Aluminum-Lithium Alloy. Master's Thesis, Dalian Jiaotong University, Dalian, China, 2005.

16. An, N.; Zhang, X.Y.; Wang, Q.M.; Yang, W.X.; Xiao, R.S. Fiber laser welding of 2060 aluminum-lithium alloy with filler wire. Chin. J. Lasers 2014, 41. [CrossRef]

17. Zhang, Y.L.; Tao, W.; Chen, Y.B. Process, microstructures and mechanical properties of double-sided fiber laser beam welded T-joints of aluminum-lithium alloys 2060 and 2099. In Proceedings of the ICALEO 2015-The 34th International Congress on Applications of Laser \& Electro-optics, Atlanta, GA, USA, 18-22 October 2015; pp. 437-445.

18. Ning, J.; Zhang, L.J.; Bai, Q.L.; Yin, X.Q.; Niu, J.; Zhang, J.X. Comparison of the microstructure and mechanical performance of 2A97 Al-Li alloy joints between autogenous and non-autogenous laser welding. Mater. Des. 2017, 120, 144-156. [CrossRef]

19. Han, B.; Chen, Y.B.; Tao, W.; Li, H.; Li, L.Q. Microstructural evolution and interfacial crack corrosion behavior of double-sided laser beam welded 2060/2099 Al-Li alloys T-joints. Mater. Des. 2017, 135, 353-365. [CrossRef]

20. Chen, D.L.; Chaturvedi, M.C. Effects of welding and weld heat-affected zone simulation on the microstructure and mechanical behavior of a 2195 aluminum-lithium alloy. Metall. Mater. Trans. A 2001, 32, 2729-2741. [CrossRef]

(C) 2019 by the authors. Licensee MDPI, Basel, Switzerland. This article is an open access article distributed under the terms and conditions of the Creative Commons Attribution (CC BY) license (http://creativecommons.org/licenses/by/4.0/). 